\title{
Using BIM as a Tool to Teach Construction Safety
}

\author{
Biemo W. Soemardi ${ }^{1, *}$, and Ray G. Erwin ${ }^{2}$ \\ ${ }^{1}$ Faculty of Civil and Environmental Engineering, Bandung Institute of Technology, Indonesia \\ ${ }^{2}$ Graduate Student, Civil Engineering, Bandung Institute of Technology, Indonesia
}

\begin{abstract}
The advancement of computer technology allows the construction education to exploit the various teaching strategies. Unlike other engineering subjects, teaching construction subjects often requires media beyond traditional class room environment that would enable the creation of field-like construction atmosphere. Construction visualization allows students to exercise and experience various field settings that are too difficult to deliver using traditional teaching approach. This paper aims at describing an attempt to develop and implement building information modelling (BIM) as a platform for teaching construction safety. Using BIM technology students can learn various aspects of safety in construction, which are typically hidden from project documents. Visualization features in BIM are utilized by students to help them identifying potential hazard, unsafe acts, and unsafe conditions in a simulated construction project. The result shows that students are more aware and capable to identify any potential hazard and related safety regulations of construction plan and design pertinent to specific site conditions than that if they were only equipped with a set of construction drawings and specifications.
\end{abstract}

\section{Introduction}

Its apparent that teaching engineering subjects often requires learning media beyond traditional classroom environment that would enable the creation of field-like environment. One of the challenges in teaching construction safety is to raise students' awareness of the importance of creating safe construction workplace by avoiding or minimizing potential accident. While theory and knowledge can be taught through traditional learning method, it is believed that forming correct attitude toward work safety and accident can effectively be done through the creation of an atmosphere in which students can as much as possible be experiencing what are perceived as unsafe acts or conditions. Within the context of construction safety, the creation of positive safety culture rests on the attitude of individuals engaged in the construction, which is the compound reflection of personal behaviour, knowledge, and environment/situation factors [1].

\footnotetext{
* Corresponding author: b_soemardi@si.itb.ac.id
} 
Construction safety is commonly taught using texts and manuals on safety issues, such as those from OSHA [2], ILO [3] and many other sources. Using this approach students are expected to learn and understand various aspects of occupational safety and health based on the teaching material provided. Yet, the questions remain; how effective is this learning method, will then the students capable of identifying and adequately responding to safety issues in the construction field? To cope with this, instructors can bring students to the construction field to get direct exposure of field conditions, and/or alternatively examine construction documents. In most cases, instructors used the latter approach to teach students to identify potential hazards in a construction project. However, as the complexity of the construction project increases, the use of $2 \mathrm{D}$ or $3 \mathrm{D}$ construction drawings will no longer sufficient, and the needs for alternative learning approach becomes apparent.

\section{BIM and Construction Safety}

The advancement of computer technology has enabled construction educators to bring the actual construction field environment closer to the classroom. Visualization technology allows students to exercise and experience various field settings that are too difficult to deliver using traditional teaching approach. BIM technology is deemed as a tool to help students to understand safety issues in construction project by means of enhanced visualization of the construction process. With all of its rich visual features, BIM technology can be regarded as a potential learning tool to assist students to understand safety issues in construction project by means of enhanced visualization of the construction process.

\subsection{Visualization and the construction hazard}

The objective of construction safety is to provide work environment that enable the construction process to proceed without or with minimum hazard. In general, this objective can be achieved through the elimination or avoidance of unsafe condition and unsafe acts that may cause hazard. Construction hazard is natural characteristics of an object that has the potential to disrupt a process and/or cause harm or injury to people. Construction riskrelated accident is defined as the probability of disruption of process and/or harm/injury to people, which can be determined by the level of exposure to hazard and the magnitude of disruption of a construction process or injury to person. Risk of construction accident can be controlled through the following steps: 1) identification of construction hazard, 2) assessment of risk hazard, 3) control of accident risk, and 4) review of risk control implementation.

Common practices of construction hazard identification are typically done by reviewing accident reports and planning the construction process while looking at possible occurrence of unavoidable hazards and accidents. These practices involve review of design/construction drawings, trying to reveal any visual information that may lead to identification of hazards.

However, with the ever increasingly more complex design and construction process, such review of drawings has become cumbersome and less effective. Traditional 2D and 3D drawings, as well as the technical specifications, can only capable of providing limited visual information on geometry, dimension, and perhaps some information on the quality of an object under review. Paper-based drawings are also not flexible enough to allow quick changes as well as inability to describe a process. Therefore, paper-based 2D 3D drawings can only provide limited opportunities to identify potential hazard in construction, whereas other potential hazards can only be identified by means of other method. 


\subsection{BIM and visualization of construction process}

In the last decades, the application of Building Information Modelling (BIM) in building design and construction planning have grown rapidly due in part to the advancement of computer technology and acceptance of its benefits by the construction industry. BIM's powerful visualization feature has provided the construction practitioners with the opportunity to explore the richness of information derived from a design object, far beyond the capability of a traditional 3D modelling. BIM technology allow design engineers and construction planners to exercise various design and construction scenarios.

In the area of construction safety, the applications and researches on BIM has also been widely recognized, focusing on the planning and design phases to improve safety during construction by connecting construction safety issues to construction planning [4], [5], and [6]. BIM-based modelling and 4D simulation allow design engineers to exercise various design alternatives that best address safety issues, as well as determining whether any proposed design change is integrated into final construction plans. BIM can even include automated safety rule-checking algorithms for identifying potential hazards [7] or integrating BIM with other technology such as location tracking and augmented reality as part of integrated construction safety management and visualization system [8].

Using BIM technology design engineers and construction planners can develop and review various scenarios of construction process within different site conditions and layouts. Based on the visual information provided by BIM they then can identify potential hazards and to propose solutions.

\section{Methodology}

This study aims at improving students' ability to improve students understanding on the importance of safety in construction worksite. Specifically, this study was designed to enhance students' ability to better identify potential hazards in a construction project by means of BIM visualization of construction process. In this study, a hypothetical construction project was used to be examined the students. The object being studied is a simple building structure located in a sloping site surrounding by some trees and other objects. Prior taking this assignment students must have already acquired basic knowledge of construction engineering and blueprint reading. First, the students were to identify as many potential hazards as possible based on a set of typical paper-based construction drawings, afterward they were assigned with the same task but equipped with the digital BIM version of the design. After reviewing the project, identified hazards were compared to determine any improvement in the ability to identify potential construction hazards.

The methodology to identify potential construction hazards using BIM is as follow:

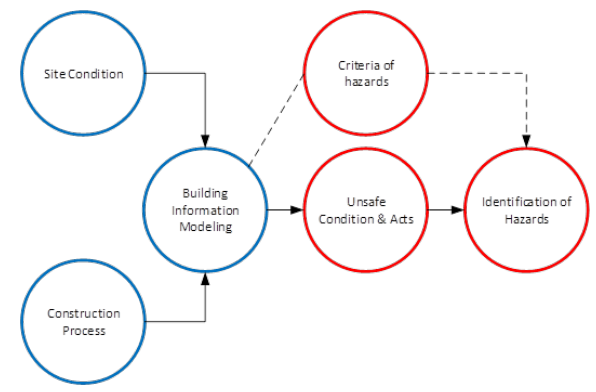

Fig. 1. Framework for BIM construction hazard identification. 
Basic information on site condition is developed from 3D design drawings. Additional information is latter added into based on site observation, such as existing structures, utility lines or other physical obstacles. At the same time, identification of construction process is developed based on knowledge and understanding of traditional construction methods. These two components are then stored in BIM databases as the basis for analysing the potential construction hazards.

To gain better understanding of the construction site, students are allowed to observe the construction site. On the next step, the students are asked to develop criteria and define the conditions that make construction accident possible based on types of hazard in OSHA Job Hazard Analysis [9]. From 25 types of potential hazards, the assignment was to identify as many construction accidents as possible based on only four types of hazard, which are fall (slip, trip), excavation (collapse), struck by (mass acceleration), and moving objects. The types of hazard were limited to the top four most frequent accidents. For each type of hazard, having basic knowledge of construction safety and the site condition, students were asked to make what-if-analysis of the construction process and site conditions based on their interpretation and understanding of project documents (drawings) and BIM model. This what-is-analysis aimed to determine possible existence unsafe conditions and unsafe acts.

\section{Analysis of BIM for Hazard Identification}

One of many approaches to control accident is by carefully planning the design that focuses on the creation of safe work environment based on the principle of prevention through design (PTD). BIM allows to bring knowledge of construction site into the design [10]. In this case, design is described as visual representation of a process toward the realization of object. PTD principles ensure that accident can prevented before the real construction process is executed, by ways of providing prior information on where and what would be the un-safe conditions and/or un-safe acts happen, so that prevention actions can be planned.

\subsection{Visual parameter for hazard identification}

To facilitate that design that can be utilized to prevent accident and to assist identifying potential location of hazards, as set of visual parameters must be set.

Table 1. Visual characteristics of prevention through design

\begin{tabular}{|c|c|c|}
\hline $\begin{array}{c}\text { BIM visual } \\
\text { parameter }\end{array}$ & description & application \\
\hline writing and symbols & number, words, sentences, sign & label, type, property, symbol \\
\hline $\begin{array}{c}\text { dimension and } \\
\text { geometry }\end{array}$ & $\begin{array}{c}\text { line, distance, volume, elevation, } \\
\text { height, depth }\end{array}$ & $\begin{array}{c}\text { to observe working/equipment zones, } \\
\text { distance between object, collision of } \\
\text { two or more objects, clear zone, } \\
\text { workspaces, opening/holes }\end{array}$ \\
\hline animation & imitation of movement of objects & $\begin{array}{c}\text { to represent walkthrough (emergency } \\
\text { route), work progress }\end{array}$ \\
\hline colour & $\begin{array}{c}\text { visual impressions that are } \\
\text { reflection of light from objects }\end{array}$ & $\begin{array}{c}\text { to provide indicators/location of } \\
\text { hazards }\end{array}$ \\
\hline shading & $\begin{array}{c}\text { colour intensity on the surface of } \\
\text { objects exposed to light }\end{array}$ & $\begin{array}{c}\text { to locate area of hazards due to lack of } \\
\text { insufficient visibility }\end{array}$ \\
\hline texture & $\begin{array}{c}\text { surface condition of objects } \\
\text { (rough, smooth, reflective, etc.) }\end{array}$ & $\begin{array}{c}\text { to identify surface of objects with } \\
\text { potential hazards }\end{array}$ \\
\hline
\end{tabular}


All those visual characteristics are facilitated in BIM features, whereas traditional drawings are mostly limited to the first two, which in turn limits the possible identification of construction hazards.

\subsection{Hazard potential analysis using BIM}

3D models with high detail and complex shading and colour provide better representation of object under study, in contrast to what can be derived from paper-based drawings. The situation surrounding the object are better represented that enables students to experience the near-actual complexity of the actual site condition. The size and positions of objects (trees, fence, etc.) give more information on the intricate condition of the site under observation that lead to better chance to identify potential hazards.
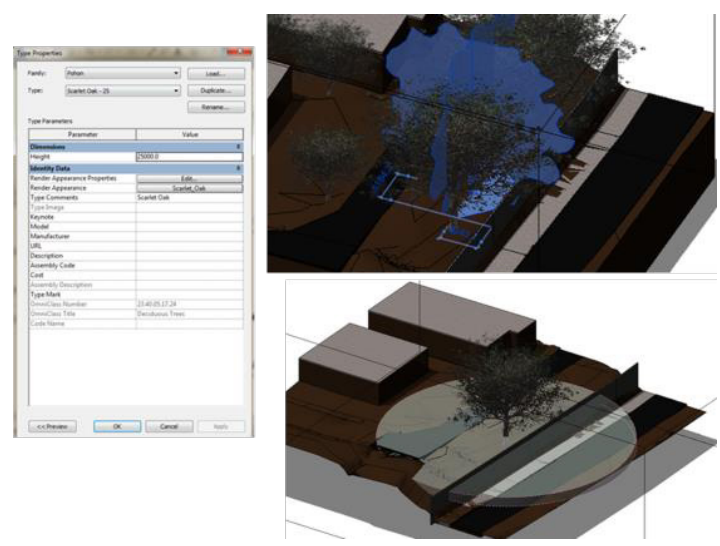

Fig. 2. Construction site situation.

BIM's 3D geometric representation gives the students the opportunity to better recognize the characteristics of elevation and slope of the site than that of lines of contour in traditional drawings. This information helps them to identify potential hazard stems from elevation differences, such as fall and slippage. In addition, other visual parameters such as symbol/sign and texture of objects also enhance the quality of information about the object and the adjacent constraints. Physical and mechanical property of soil, for instance, can be used by the students to determine whether the soil where an object is located has the potential to cause an accident, such as collapse.

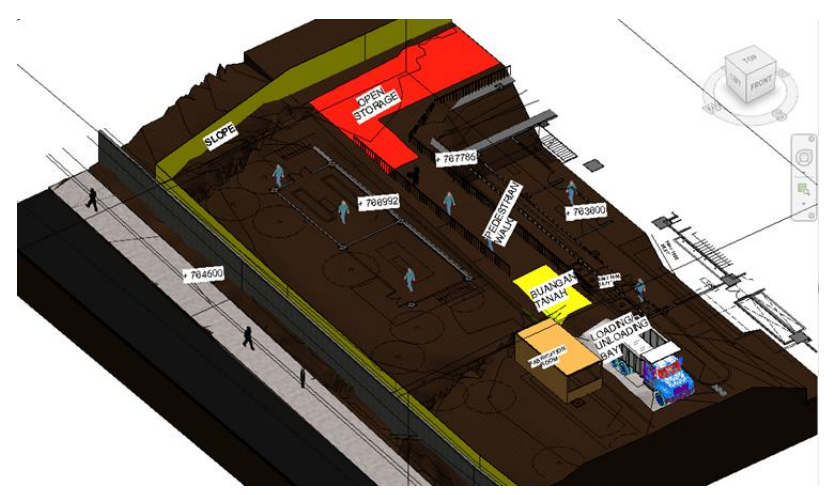

Fig. 3. Animation of construction traffic. 
Animation is an important feature of BIM that enables students to exercise various scenarios of construction process and examine the consequences with regards to the potential existence of construction hazards. As an example, students designed flow of traffic in construction sites, where they can examine potential accident involving vehicles and workers, as well damages to properties. Here collision detector feature of BIM can be used to accurately position objects within spaces.

\subsection{Hazard identification using BIM}

3D capability of BIM can provide the representation of geometric form of topography of the construction site and other objects. By combining this geometric information with other parameters (such as property of soil and other objects) students can determine whether a particular location is potential to become an unsafe condition that may lead to an accident, such as falling from higher elevation. On the other side, BIM's animation feature can be used to exercise the possible emergence of unsafe acts at a certain site condition.

The construction hazard in the form of struck by objects, which primarily in the form of falling objects can be identified by BIM technology. In addition to the potential location of unsafe condition, the severity of hazard can be further determined by examining the information about the height of fall, weight and other characteristic of the falling objects, such types of object (liquid, solid metal, fine grains), physical property (sharp edges, rough surface texture etc.), and any other property. This information can be stored and later retrieved from BIM database.

Excavation hazards are commonly resulted from unsafe conditions and/or unsafe acts around excavation area. The potential and severity of excavation hazards is influenced by geometry and dimension of excavation as well as the property of excavated material (density, friction coefficient, water content, etc.). BIM technology allow students to identify the potential hazard by examining the height of excavation and information about the characteristics and mechanical property of material, which can be retrieved from BIM database.

Students can also BIM visualization to identify potential hazard from movement of objects. Hazard from movement objects can be identified using the animation feature of BIM. In addition to utilizing collision detector feature to determine safe perimeter, the use of colour and geometry parameters in BIM can be used to design path for moving objects and safe zones. Students can utilize different colour to assign different degrees of safe zone associated with different kind of moving objects.

BIM allows student explore conditions that are no available in traditional approach. to exercise the consequence of a construction action. For example, inappropriate installation of construction ladder has the potential of falling. Such condition can only be experienced by students through the use BIM technology, while to who rely on traditional paper-based drawings and specification will find difficulty to visualize.

Students can also study the effect for natural light to the construction site. Site clarity will influence the ability to visually identify potential hazard. Solar study feature in BIM technology helps students to identify site potential hazards because of lack of illumination. As the sun moves during the construction progress, the students can experience different clarity of site visibility. 


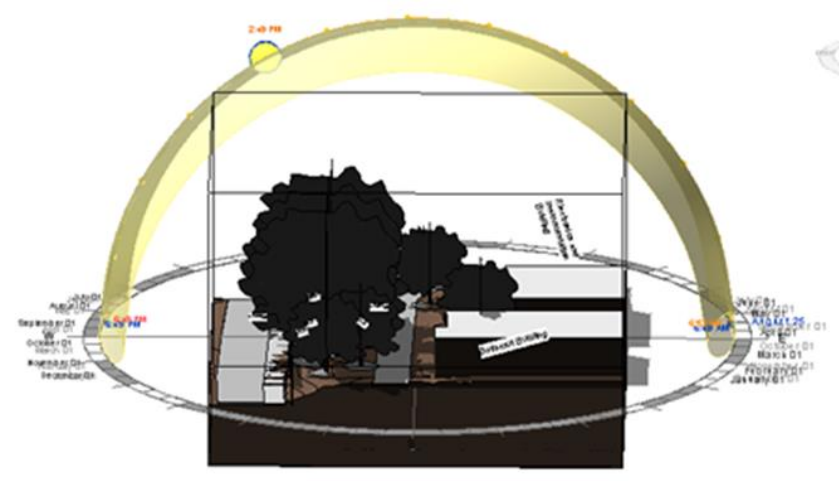

Fig. 4. Solar study of construction site.

In summary, by using BIM technology students were able to identify 64 potential construction hazards. This is significantly higher than number of potential hazards that can be identified using traditional paper-based construction drawings.

Table 2. Potential construction hazards

\begin{tabular}{|c|c|}
\hline Hazard & frequency \\
\hline Fall (trip/slip) & 28 \\
\hline Falling objects & 21 \\
\hline Movement of objects & 9 \\
\hline Excavation & 6 \\
\hline
\end{tabular}

The significant improvement in identifying hazard by using BIM technology as opposed to using traditional design drawings are hazards related to fall, falling object and movement of objects. Students are able to identify more fall and falling object hazards because they are provided with more detailed and comprehensive information about the characteristics of the objects. Animation, which is not available in traditional design drawings clearly has the advantages for identifying hazards related to movement objects. Although students can make prediction of potential hazard resulting from the movement of objects in a space using traditional design drawings, they were not sure about the correctness and accuracy.

\section{Conclusion}

It is clear that visualization plays important role in understanding object under certain conditions. BIM allows student to experience the sensation of depth and other physical site condition that are absent in the traditional paper-based drawings. The higher the quality and accuracy of the information, the better and more comprehensive understanding of the students toward the objects under study. More features in visual representation enables students to explore their imagination and creativity. However, there are conditions that must be met before allowing students to explore the potential of BIM. BIM technology is expensive and students must be better prepared and equipped with knowledge and principles of construction practices as well as understanding the principles of construction safety. Such conditions are necessary to prevent students from excessively exploiting the 
capability of BIM without clear understanding the principles of prevention through design to address construction safety issues.

\section{References}

1. R. M. Choudhry, D. Fang, and S. Mohamed, Developing a Model of Construction Safety Culture, Technical Notes, J. of Mgt. in Eng., Vol 23 Issue 4, pages 207 (2007)

2. OSHA, Recommended Practices for Safety \& Health Programs in Construction, (2016)

3. ILO, Training package in occupational safety and health for the construction industry, (2010)

4. M. Weinstein, J. Gambatese, and S. Hecker, Can Design Improve Construction Safety? Assessing the Impact of a Collaborative Safety-in-Design Process, J. of Const. Eng. and Mgt., Volume 131 Issue 10, pages 1125-1134 (2005)

5. Sulankivi, K. Kähkönen, K. Mäkelä, and T. Kiviniemi, M., 4D-BIM for Construction Safety Planning, Proceedings W099 - Special Track 18th CIB World Building Congress, Salford, United Kingdom, pages 117-128, (2010)

6. W. Zhoua, J. Whytea, and R. Sacks, Construction safety and digital design: A review, Automation in Construction, Volume 22, Pages 102-111, (2012)

7. S. Zhanga, K. Sulankivib, M. Kiviniemib, I. Romoc, C. M. Eastmand, and Jochen Teizere, BIM-based fall hazard identification and prevention in construction safety planning, Safety Science, Volume 72, Pages 31-45 (2015)

8. Chan-Sik Park, and Hyeon-Jin Kim, A framework for construction safety management and visualization system, Automation in Construction, Volume 33, Pages 95-103 (2013)

9. OSHA, Job Hazard Analysis, 3017, revised edition (2002)

10. A. Ganah and J. A John, Integrating Building Information Modeling and Health and Safety for Onsite Construction, J. Safety and Health at Work, Volume 6 Issues 1, pages 39-45 (2015) 